\title{
Casas Navarro, Raymundo. (2009). Redacción General. Un enfoque pragmalingüístico (2 ed.). Lima: Megabyte.
}

El libro de Raymundo Casas, Redacción General, aborda el proceso de la redacción con relación a la pragmática, los principios textuales, la retórica y la argumentación, sin dejar de lado los aspectos de la ortografía, gramática, y, a la vez, ofrece un panorama de la redacción científica y administrativa. El libro que nos presenta Casas se concentra en una de las prácticas lingüísticas que hacemos los humanos: componer escritos, dar cuerpo y sentido a nuestras ideas y conocimientos, para otorgarles ropaje lingüístico, y ponerlos al alcance del público lector.

En la actualidad, nos damos cuenta de que iniciar en la redacción no es simplemente aplicarnos a ella, o tener un esfuerzo por escribir, sino que es imprescindible conocer las pautas que dirijan su accionar: la información exige organización, la persuasión nos exige conocer las figuras retóricas, el convencimiento nos exige conocer de nociones generales de argumentación. Es decir, la práctica escribal nos exige conocer una serie de presupuestos teóricos para dirigir el orden y la plasmación de nuestras ideas, peticiones, saberes y deseos. La comunidad letrada dirige la práctica de la escritura. En este sentido, el libro de Casas nos entrega todas estas pautas teóricas necesarias para tener en cuenta en la redacción. En el libro, Casas se traza un objetivo básico: presentar lineamientos teóricos que encaminen a la pedagogía de la redacción, sobre la base de un enfoque específico: la pragmática, entendida como el uso del lenguaje en relación con factores extralingüísticos. El hecho de escribir no está exento de la influencia de la recepción de lo escrito, del mismo receptor, de la relevancia de la información, de la cortesía, de la forma de cooperar en la transmisión de la información, del espacio en el que se circunscribe lo escrito, de la referencia a los elementos de la comunicación. Redactar implica la interrelación entre la utilización del lenguaje escrito y el contexto comunicativo. Redactar es un acto humano que le sirve al hombre para muchos propósitos y efectos como establecer un contacto, dar a conocer una noticia o un invento, e incluso, trascender en la historia humana. En este sentido, es llamativo el subtítulo del libro de Casas: «Un enfoque pragmalingüístico», pues nos advierte que lo meramente lingüístico requiere de la comprensión del componente pragmático que le da un sentido característico. Es rescatable del autor que la didáctica de la redacción deba abordarse desde este enfoque pragmalingüístico, en tanto que el hombre como hablante potencialmente creativo se sitúa en el marco y en 
la intención comunicativa. Según Casas, «La redacción es una herramienta de la comunicación, no de la incomunicación».

Redacción General se compone de ocho capítulos. En cada uno de ellos, se presencia la importancia e implicancias del arte de redactar, y se contempla los vínculos que se establece a partir de la redacción con la gramática, la argumentación y la retórica, por ejemplo.

En el capítulo uno, «Pragmática y redacción», el autor ofrece una relación entre la redacción y la comunicación, y da a entender que el arte de redactar no está divorciado del uso del lenguaje. Frente a ello, resulta interesante que proponga la noción de «redacción cooperativa»: el redactor no debería perder de vista que el texto se dirige a un receptor y, por ende, debe siempre intuir más o menos cómo es este lector ideal. En este contexto, el autor logra aplicar audazmente las máximas conversacionales de Grice al campo de la redacción: al redactar, la información expuesta debe ser tan informativa como la situación lo exija, cuidar de no presentar información falsa, no interpolar comentarios impertinentes, seguir una determinada estructura para garantizar la eficacia de la transmisión; es decir, el redactor debe ajustarse siempre al contexto comunicativo.

En el capítulo dos, «Principios textuales de la redacción», Casas señala que la redacción entraña una construcción textual, al reconocer las propiedades textuales, comprenderemos el proceso general de la redacción. Para ello, parte de una noción pragmática de texto, como una ristra de enunciados con una intención comunicativa que lo gobierna; y, en seguida, se concentra en los pilares de la coherencia y la cohesión. La organización e inteligibilidad textual requiere del conocimiento y garantía de la estructuración y conexión de los enunciados. Respecto de la coherencia, el autor nos dice que no solo es asunto de la semántica, sino también de la pragmática, pues el texto se relaciona con los conocimientos aceptados, los requisitos conceptuales y el trasfondo cultural; es decir, la coherencia pragmática del texto depende de la información extratextual. Respecto de la cohesión, el autor incide en los marcadores discursivos: los conectores y los marcadores extratextuales. Estos últimos no solo organizan el texto, sino también lo reformulan o indican que el texto ha sufrido una interpolación.

En el capítulo tres, «Retórica de la redacción», se apuntala el vínculo que adquiere la redacción con la retórica. Para construir escritos o discursos persuasivos, es muy útil manejar las herramientas ofrecidas por la retórica. En este capítulo, se presentan las operaciones retóricas, conjunto de acciones que conducen a la elaboración del texto, desde la fase inicial de búsqueda de ideas hasta la fase 
final de defensa o de exposición; y la estructura discursiva del texto retórico, la configuración textual para ordenar las ideas y los efectos deseados. En el eje de las operaciones retóricas, se encuentra la intellectio o la comprensión del tema, la inventio o la elaboración de ideas, la dispositio o el orden de ideas y la elocutio o la verbalización. En la elocutio, se localizan las cualidades de una buena elocución: puritas (pureza), perspicuitas (nitidez), urbanitas (moderación) y ornatus (ornato, el embellecimiento del discurso, a través de las figuras del discurso: figuras de dicción y figuras de pensamiento). En el eje del texto retórico, se presenta la organización del discurso retórico: exordium (presentación), narratio (narración de los hechos), argumentatio (argumentación) y peroratio (recapitulación). Ambos ejes, dice el autor, son cruciales para confeccionar un buen desarrollo textual y se debe tener presente que la competencia en la redacción depende del nivel logrado en ambos ejes.

De acuerdo con el capítulo cuatro, «Ortografía y redacción», la redacción no puede desentenderse de las consideraciones ortográficas. La redacción es una forma de comunicación y los criterios normativos garantizan, en gran parte, esta inteligibilidad. Casas nos dice que la lengua castellana cuenta con la normatividad establecida por la Real Academia de la Lengua Española, que si bien, algunas veces, cae en la incoherencia, es el referente para nuestras reflexiones sobre la ortografía. En este apartado, se presentan los fundamentos de la ortografía castellana: el criterio etimológico, el criterio fonético y el criterio de uso. Este último resulta bastante considerable porque suele imponerse por encima de los dos anteriores. El autor apuesta por el criterio de uso, pues como dicen «el amo es el uso» y debe dársele cabida. El autor presenta, asimismo, los niveles de la ortografía castellana: ortografía de la letra, ortografía de la palabra y ortografía del enunciado. Este último punto es clave para la redacción, dado que para construir textos es necesario conocer el empleo de la puntuación y tener en cuenta, al mismo tiempo, los efectos de la comunicación. La puntuación contribuye con la interpretación y la desambigüedad textual.

En el capítulo cinco, "Gramática y redacción», se repasa algunos tópicos relevantes de la gramática que tiene mayor incidencia en la redacción. Para Casas, la redacción depende fuertemente del conocimiento de la gramática normativa. Así, el autor enfatiza en los temas del dequeísmo y queísmo, los casos especiales de concordancia nominal, concordancia verbal y en la consecutio témporum o concordancia de tiempos. Escribir un texto supone el conocimiento de los aspectos gramaticales en general. 
El capítulo seis, «Redacción y argumentación», versa sobre el papel gravitante de la argumentación para el arte de redactar. En el proceso de la redacción, hay que poner atención a la argumentación, que reposa en el vínculo ente premisas y conclusión. Para ello, el autor expone el modelo o la gramática de la argumentación: que contiene a la argumentación simple, cuando una conclusión se basa en una sola premisa, y a la argumentación múltiple, cuando la conclusión se apoya en un conjunto de premisas. En este contexto, Casas incorpora los indicadores de fuerza argumentativa, como son, por ejemplo, los de introducción de opinión («se sigue de todo lo anterior que...») y de justificación («considerando que...»). En este capítulo, añade el tema de las falacias, como argumentaciones que transgreden un principio o una regla de razonamiento, y no como un conjunto de proposiciones falsas, como algunos están acostumbrados a creer. Las falacias como argumentaciones rompen el vínculo entre premisas y conclusión: la conclusión no se sigue o no se establece a partir de las premisas planteadas.

En el capítulo siete, «Redacción administrativa», se presenta recomendaciones sobre la composición de documentos administrativos, tales como la solicitud, la carta notarial, el informe, entre otros. Casas sugiere, por ejemplo, que al redactar un documento administrativo se debe emplear con transparencia los verbos que indican la acción y debería evitarse el abuso de la sustantivización. Así, es preferible «El señor López, a partir de mañana, supervisará a los trabajadores de la planta» que la forma «El señor López, a partir de mañana, va a ejercer la supervisión a los trabajadores de la planta».

$\mathrm{Y}$, en el capítulo ocho, «Redacción en la ciencia», el autor nos expone los contenidos vitales sobre la redacción aplicada a la actividad científica, como es la organización de un esquema de exposición una vez concluido el recojo de los datos. En este capítulo, es sugestivo la descripción y las pautas que se ofrecen para componer el ensayo científico, la tesis universitaria, el proyecto de tesis y el artículo científico. En el contexto del artículo científico, el autor subraya que no todas las producciones científicas deben sujetarse absolutamente al mismo molde de estructuración, lo más importante en la ciencia son las ideas. El autor otorga flexibilidad al corsé de la estructuración de los artículos científicos, por ejemplo, los artículos humanísticos no tienen que seguir necesariamente el ordenamiento de un artículo sobre un experimento científico, y se inclina por la difusión del conocimiento.

En líneas generales, Redacción general escrito por Raymundo Casas enfatiza, desde una perspectiva teórica, el arte de redactar y su engarce con los componentes 
pragmáticos, textuales, argumentativos, administrativos y científicos. Frente a la abundancia de materiales prácticos sobre redacción, es sorprendente la aparición de un texto que profundice en los supuestos teóricos de cómo redactar y las consecuencias que de ello se desprende, más aún si la orientación transversal del libro es el enfoque pragmático. En este sentido, la obra de Casas cobra valor y es bienvenida en el campo de la redacción. El libro Redacción General es una obra importantísima y anclada en el tiempo en tanto que orienta la práctica cotidiana y masiva de la redacción castellana. El libro, incluso, en sí mismo, es ejemplo de una excelente redacción, es un modelo de lo que significa redactar.

Por último, es significativo que el autor, Raymundo Casas, nos deje un mensaje sugerente: con la reflexión teórica y el ejercicio constante, uno puede lograr mejorar en el arte de la redacción. Al analizar los pilares fundamentales de la redacción, se logra la eficacia en la práctica cotidiana del escribir.

Marco Lovón Cueva 